Supplement of Atmos. Chem. Phys. Discuss., 15, 16715-16745, 2015

http://www.atmos-chem-phys-discuss.net/15/16715/2015/

doi:10.5194/acpd-15-16715-2015-supplement

(C) Author(s) 2015. CC Attribution 3.0 License.

(c) (i)

\title{
Sea salt aerosols as a reactive surface for inorganic and organic acidic gases in the arctic troposphere
}

\section{J. W. Chi et al.}

Correspondence to: J. W. Chi (liweijun@sdu.edu.cn) and Y. M. Zhang (ymzhang@cams.cma.gov.cn)

The copyright of individual parts of the supplement might differ from the CC-BY 3.0 licence. 
Table S1 Sampling dates, sampling times, and meteorological conditions for 23 samples

\begin{tabular}{|c|c|c|c|c|c|c|c|}
\hline No. & $\begin{array}{c}\text { Sampling } \\
\text { date }\end{array}$ & $\begin{array}{l}\text { Sampling } \\
\text { time }\end{array}$ & $\begin{array}{c}\mathrm{T} \\
\left({ }^{\circ} \mathrm{C}\right)\end{array}$ & $\begin{array}{l}\text { RH } \\
(\%)\end{array}$ & $\begin{array}{c}\text { Air pressure } \\
(\mathrm{hPa})\end{array}$ & $\begin{array}{c}\text { Wind } \\
\text { direction }\end{array}$ & $\begin{array}{l}\text { Wind speed } \\
\qquad(\mathrm{m} / \mathrm{s})\end{array}$ \\
\hline 1 & Aug.4, 2012 & 9:06-9:36 & 4.7 & 82 & 1002.1 & 330 & 4.1 \\
\hline 2 & Aug.4, 2012 & $21: 00-21: 20$ & 3.7 & 85 & 1001.9 & 309 & 5.3 \\
\hline 3 & Aug.5, 2012 & $14: 53-15: 14$ & 5.6 & 75 & 1002.6 & 95 & 1.8 \\
\hline 4 & Aug.7, 2012 & 20:50-21:15 & 4.9 & 84 & 1009.0 & 296 & 4.1 \\
\hline 5 & Aug.8, 2012 & 8:23-8:48 & 4.9 & 81 & 1007.6 & 238 & 2.1 \\
\hline 6 & Aug.9, 2012 & $15: 20-15: 49$ & 7.0 & 78 & 1003.5 & 120 & 7.3 \\
\hline 7 & Aug.10, 2012 & $0: 15-0: 40$ & 7.3 & 80 & 998.6 & 135 & 8.9 \\
\hline 8 & Aug.11, 2012 & 9:10-9:35 & 6.2 & 94 & 997.0 & 303 & 3.3 \\
\hline 9 & Aug.12,2012 & $16: 00-16: 25$ & 6.6 & 80 & 1006.8 & 129 & 5.9 \\
\hline 10 & Aug.13, 2012 & $9: 25-9: 50$ & 5.1 & 82 & 1010.0 & 141 & 0.0 \\
\hline 11 & Aug.13, 2012 & $14: 15-14: 40$ & 4.5 & 90 & 1011.4 & 351 & 2.1 \\
\hline 12 & Aug.14, 2012 & $15: 12-15: 42$ & 4.6 & 88 & 1020.5 & 117 & 2.6 \\
\hline 13 & Aug.14, 2012 & $21: 17-21: 47$ & 4.8 & 84 & 1020.7 & 276 & 5.4 \\
\hline 14 & Aug.15, 2012 & 18:45-19:31 & 6.0 & 70 & 1018.9 & 88 & 3.3 \\
\hline 15 & Aug.17, 2012 & 9:00-10:00 & 3.8 & 86 & 1017.1 & 116 & 0.3 \\
\hline 16 & Aug.17, 2012 & $14: 50-15: 20$ & 3.7 & 85 & 1015.7 & 109 & 2.2 \\
\hline 17 & Aug.18, 2012 & $15: 30-16: 15$ & 5.7 & 83 & 1020.3 & 23 & 1.5 \\
\hline 18 & Aug.19, 2012 & $15: 30-16: 10$ & 6.0 & 72 & 1010.0 & 212 & 4.9 \\
\hline 19 & Aug.19, 2012 & 21:10-21:45 & 6.1 & 74 & 1004.1 & 297 & 2.2 \\
\hline 19 & Aug.20, 2012 & 9:00-9:40 & 3.6 & 77 & 1008.5 & 334 & 2.6 \\
\hline 20 & Aug.20, 2012 & $15: 10-15: 50$ & 4.3 & 72 & 1004.7 & 315 & 7.5 \\
\hline 21 & Aug.21, 2012 & $15: 05-15: 40$ & 1.6 & 87 & 1003.7 & 314 & 6.8 \\
\hline 22 & Aug.22, 2012 & 8:55-9:30 & 2.8 & 78 & 999.2 & 331 & 2.8 \\
\hline 23 & Aug.23, 2012 & $15: 10-16: 10$ & 4.7 & 56 & 1001.3 & 105 & 4.6 \\
\hline
\end{tabular}
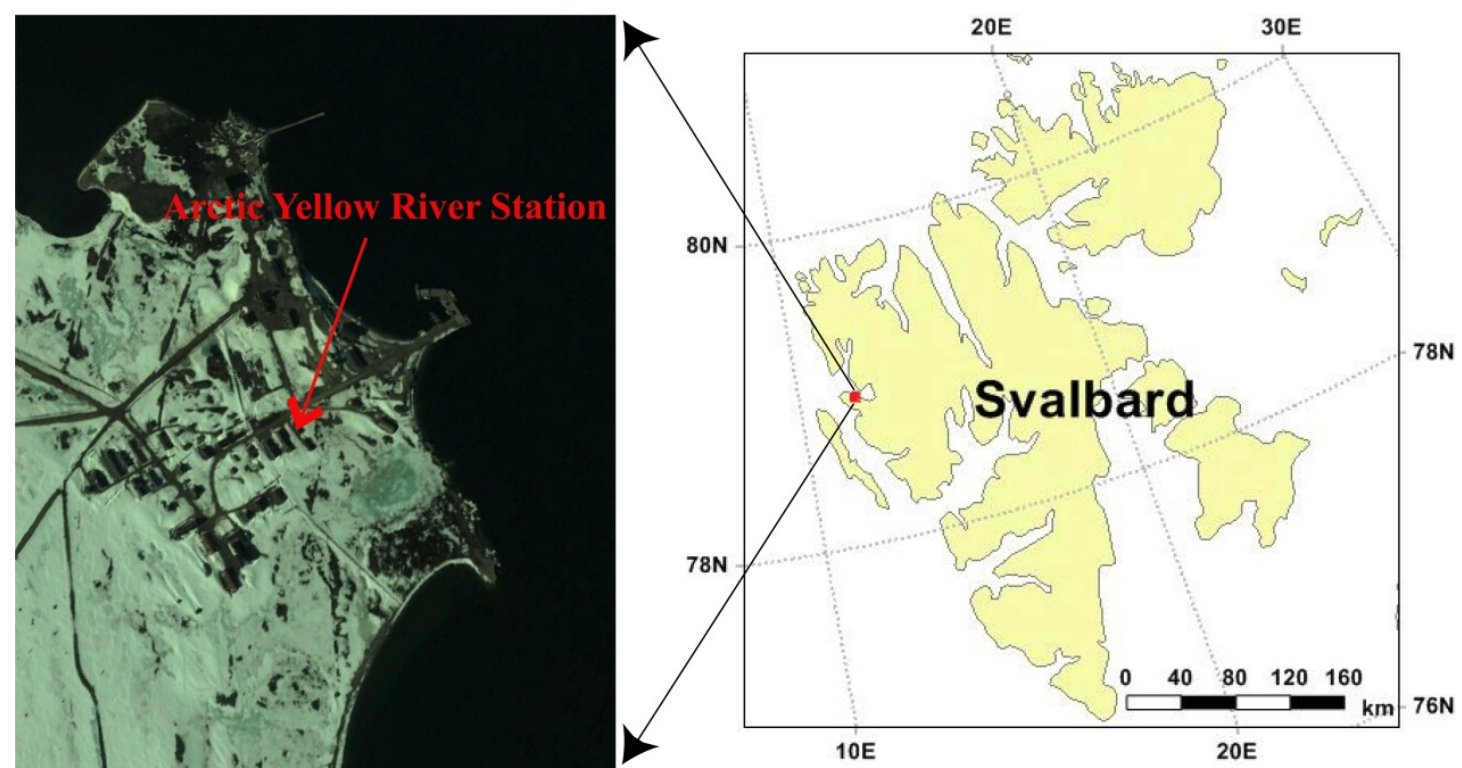

Figure S1. The location of sampling point-Chinese Arctic Yellow River Station, 
Svalbard.

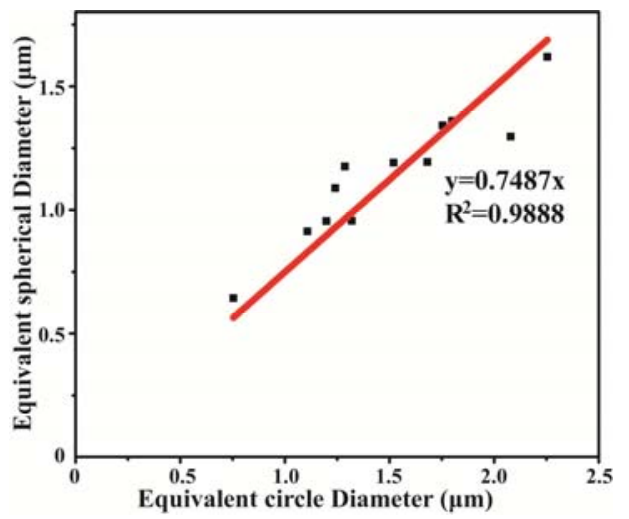

Figure S2. The correlation of equivalent circle diameter (d) and equivalent spherical diameter (D) obtained by AFM. 